\title{
Economic Uncertainty before and during the COVID-19 Pandemic
}

\author{
Dave Altig, Scott Brent Baker, Jose Maria Barrero, Nick Bloom, Phil Bunn, \\ Scarlet Chen, Steven J. Davis, Brent Meyer, Emil Mihaylov, Paul Mizen, Nick \\ Parker, Thomas Renault, Pawel Smietanka, and Greg Thwaites
}

\author{
Working Paper 2020-9 \\ July 2020
}

\begin{abstract}
We consider several economic uncertainty indicators for the United States and the UK before and during the COVID-19 pandemic: implied stock market volatility, newspaper-based economic policy uncertainty, twitter chatter about economic uncertainty, subjective uncertainty about future business growth, and disagreement among professional forecasters about future gross domestic product growth. Three results emerge. First, all indicators show huge uncertainty jumps in reaction to the pandemic and its economic fallout. Indeed, most indicators reach their highest values on record. Second, peak amplitudes differ greatly-from an 80 percent rise (relative to January 2020) in two-year implied volatility on the S\&P 500 to a 20 -fold rise in forecaster disagreement about UK growth. Third, time paths also differ: implied volatility rose rapidly from late February and peaked in mid-March, falling back by late March as stock prices began to recover. In contrast, broader measures of uncertainty peaked later and then plateaued, as job losses mounted, highlighting the difference in uncertainty measures between Wall Street and Main Street.
\end{abstract}

JEL classification: D80, E22, E66, G18, L50

Key words: forward-looking uncertainty measures, volatility, COVID-19, coronavirus

https://doi.org/10.29338/wp2020-09

The authors thank the U.S. National Science Foundation, the Sloan Foundation, the University of Chicago Booth School of Business, and the Economic and Social Research Council for financial support. They also thank Mike Clements and Martin Weale for comments on an earlier draft, Ian Dew-Becker for supplying data on the 24-month VIX, and Niall Ferguson for pointers to the literature on excess mortality in previous pandemics. This paper expands and extends parts of Baker, Bloom, Davis, and Terry (2020). The views expressed here are those of the authors and not necessarily those of the Federal Reserve Bank of Atlanta or the Federal Reserve System. Any remaining errors are the authors' responsibility.

Please address questions regarding content to dave.altig@atl.frb.org, srbaker@gmail.com, jose.barrero@itam.mx, nbloom@stanford.edu, philip.bunn@bankofengland.co.uk, sijiac@stanford.edu, Steven.Davis@chicagobooth.edu, Brent.Meyer@atl.frb.org, emil.mihaylov@atl.frb.org, Paul.Mizen@nottingham.ac.uk, nicholas.parker@atl.frb.org, pawel.smietanka@bankofengland.co.uk, and gregorythwaites@gmail.com.

Federal Reserve Bank of Atlanta working papers, including revised versions, are available on the Atlanta Fed's website at www.frbatlanta.org. Click "Publications" and then "Working Papers." To receive e-mail notifications about new papers, use frbatlanta.org/forms/subscribe. 


\section{Introduction}

Fed Chairman Jerome Powell aptly summarized the level of uncertainty in his May 21st speech noting "We are now experiencing a whole new level of uncertainty, as questions only the virus can answer complicate the outlook". Indeed, there is massive uncertainty about almost every aspect of the COVID-19 crisis, including the infectiousness and lethality of the virus; the time needed to develop and deploy vaccines; whether a second wave of the pandemic will emerge; the duration and effectiveness of social distancing; the near-term economic impact of the pandemic and policy responses; the speed of economic recovery as the pandemic recedes; whether "temporary" government interventions will become permanent; the extent to which pandemicinduced shifts in consumer spending patterns, business travel, and working from home will persist; and the impact on business formation, and research and development. ${ }^{1}$

In this light, we examine several measures of economic uncertainty before and during the COVID-19 pandemic. Our focus is on forward-looking uncertainty measures that are available in near real-time or with modest delays measured in days or weeks. We adopt this focus for three reasons. First, measures derived from statistical models fit to standard macroeconomic data are essentially backward looking. As a result, they are not well suited to quickly capture the shifts associated with sudden, surprise developments. That's especially so when key inputs to the forecasting model become available with lags measured in months and quarters. Second, backward-looking approaches to quantifying uncertainty are problematic in the near-term wake of a huge shock that lacks close historic parallels. Third, when an enormous and unusual shock hits with such suddenness, it is especially vital for real-time forecasting purposes and for policy formulation to work with measures that capture the uncertainties that economic agents actually

\footnotetext{
${ }^{1}$ On uncertainty about key parameters in epidemiological models of Covid-19 transmission and mortality, see Atkeson (2020a), Bendavid and Bhattacharya (2020), Dewatripont et al. (2020), Fauci et al. (2020), Li et al. (2020), Linton et al. (2020), and Vogel (2020). On what key parameter values imply in standard epidemiological models and extensions that incorporate behavioral responses to the disease and various testing, social distancing, and quarantine regimes, see Anderson et al. (2020), Atkeson (2020b), Berger, Herkenhoff and Mongey (2020), Eichenbaum, Rebello and Trabant (2020), Neil Ferguson et al. (2020), and Stock (2020a). On the potential for vigorous antigen and antibody testing to shift the course of the pandemic, see Romer and Shah (2020) and Stock (2020b). On stock market effects, see Alfaro et al. (2020), Baker et al. (2020) and Toda (2020). On complexities arising from highly uneven supply-side disruptions caused by a major pandemic, see Guerrieri et al. (2020). On the post-pandemic shift to working from home, see Altig et al. (2020b). On potential medium- and long-term macroeconomic consequences, see Barrero, Bloom and Davis (2020), Barro, Ursua and Weng (2020) and Jorda, Singh and Taylor (2020).
} 
perceive. The forward-looking uncertainty measures we consider can potentially meet that test in a way that backward-looking measures cannot.

\section{The Extraordinary Economic Fallout of the COVID-19 Pandemic}

To appreciate the tremendous speed and magnitude with which the COVID-19 economic crisis unfolded, consider some observations about job loss and unemployment in the United States. New claims for unemployment benefits in the early part of 2020 ranged from 201,000 to 282,000 per week through the week ending 14 March 2020. Relative to covered employment, these figures correspond to the slowest pace of new claims in the history of the series back to 1971. Over the ensuing twelve weeks, over 40 million Americans filed new claims, an astonishing surge without precedent in US history. ${ }^{2}$ As measured in the Current Population Survey, the unemployment rate rose from 3.5 percent in February 2020 - its lowest rate in over 60 years - to 14.7 percent in April, the highest rate in 80 years. ${ }^{3}$ The speed and scale of the COVID-19 employment shock dwarf any previous shock in the modern era. ${ }^{4}$

Another set of observations further underscores the lack of close historic parallels to the economic impact of the COVID-19 pandemic. The Spanish Flu pandemic a century ago offers a useful point of comparison. Barro et al. (2020) estimate that the Spanish Flu killed about 40 million people worldwide, or about 2.1 percent of the world's population. Worldwide deaths attributed to COVID-19 as of 1 June 2020 are about 366,000 on a global population base of 7.7 billon, yielding a global mortality rate of less than 0.05 percent. ${ }^{5}$ Because the flow of new deaths attributed to COVID-19 continues to rise, the ultimate death toll will surely be higher. However, even if cumulative deaths attributed to COVID-19 quadruple over the next year or two, the

\footnotetext{
${ }^{2}$ The unemployment claims data are available at https://oui.doleta.gov/unemploy/claims arch.asp. The figures cited in the text are seasonally adjusted.

${ }^{3}$ As noted in the April 2020 BLS Employment Situation Report, an unusually large number of persons classified as "employed but absent from work" during the reference week (April 12-18) for the household survey. As discussed in the FAQs at https://www.bls.gov/cps/employment-situation-covid19-faq-april-2020.pdf, it appears that many of the "employed but absent from work" were, in fact, on temporary layoff. Adding these to the $14.7 \%$ official unemployment rate for April 2020 yields and unemployment rate of 19.5 percent according to the BLS.

${ }^{4}$ The increase in unemployment has been much more modest in the UK, at least to date. That likely reflects the UK Government's Job Retention Scheme which offers to cover $80 \%$ of an employee's wages (up to $£ 2500$ a month) if they are not required to work any hours by their employer. Around one-third of private sector employees have been covered by this scheme.

${ }^{5}$ Excess mortality from 1918 to 1920 was 0.46 and 0.52 percent of population, respectively, in the UK and US (Table 1 in Barro et al., 2020). As of 1 June 2020, UK and US excess mortality rates are (59,500/66.46 million) $=$ 0.09 percent and $(71,500 / 326.69$ million $)=.02$ percent using data from the World Bank and Financial Times sources cited below.
} 
COVID-19 mortality shock will remain two orders of magnitude smaller than the one associated with the Spanish Flu.

Seen in this light, the enormous economic toll of COVID-19 is anomalous. Using annual, country-level regression models, Barro et al. (2020) estimate Spanish Flu-generated economic declines in GDP and consumption of 6 and 8 percent, respectively, in the typical country. The COVID-19 pandemic appears to be driving similar, probably larger, percentage declines. Yet the COVID-19 mortality shock is tiny compared to one caused by the Spanish Flu. Thus, in terms of economic impact relative to mortality, the current pandemic is quite unlike 1918-1920.

The Spanish Flu also unfolded in a very different social, political, and economic context than the current pandemic. Agriculture and Manufacturing accounted for 61 percent of employment then, as compared to 10 percent now (Velde, 2020). The first wave of the Spanish Flu in Spring 1918 occurred during the last stages of World War I, and the deadlier second wave from September 1918 to February 1919 overlapped with the end of the war and the demobilization of troops. These contemporaneous developments complicate efforts to assess the economic effects of the Spanish Flu. Partly to address this challenge, Velde (2020) draws on a variety of highfrequency data to assess the short-term economic impact of the Spanish Flu in the United States. He concludes that "the pandemic coincided with, and very likely contributed to a mild recession from which the economy quickly rebounded." Thus, his analysis only sharpens the contrast between the economic fallout of the Spanish Flu and the huge contraction in the wake of the far less lethal COVID-19 pandemic.

In terms of mortality, the COVID-19 pandemic is much closer to more recent influenza pandemics, as stressed by Niall Ferguson (2020). The US Center for Disease Control estimates that the 1957-58 and 1968 influenza pandemics caused 116,000 and 100,000 excess deaths in the United States. ${ }^{6}$ Scaling by population yields excess mortality rates of 0.067 percent in 1957-58 and 0.050 percent in 1968 . As of 1 June 2020, the US excess mortality rate during the COVID19 episode is $(71,500 / 326.69$ million $)=.02$ percent of the population. ${ }^{7}$ Thus, if the COVID-19

\footnotetext{
${ }^{6}$ See www.cdc.gov/flu/pandemic-resources/1957-1958-pandemic.html and www.cdc.gov/flu/pandemicresources/1968-pandemic.html. Glezen (1996) reports similar estimates for excess mortality in the 1957-58 and 1968 pandemics and discusses the concept of excess mortality.

${ }^{7}$ The excess mortality figure is from www.ft.com/content/a26fbf7e-48f8-11ea-aeb3-955839e06441, accessed 1 June 2020, and the population figure is from the World Bank at https://data.worldbank.org/indicator/SP.POP.TOTL.
} 
death toll in the United States ultimately triples, it will reach excess mortality rates comparable to the US experience in 1957-58 and 1968 and only one-tenth its rate during the Spanish Flu. ${ }^{8}$ Yet, as Niall Ferguson (2020) underscores, the 1957-58 pandemic imparted a mild impact on aggregate economic activity, and it was not seen as a significant macroeconomic factor by contemporaneous observers. Similarly, US employment and output grew at a healthy pace during 1968, showing no visible reaction to the influenza pandemic. Thus, these more recent pandemics also offer a startling contrast to the enormous economic contraction triggered by COVID-19. ${ }^{9}$

To summarize, the economic response to the COVID-19 pandemic is unprecedented in at least two respects: First, the suddenness and enormity of the economic shock, most visibly represented in the massive job losses and, second, the severity of the economic contraction relative to the size of the mortality shock. The US stock market has also reacted with much greater force and volatility to COVID-19 than any other pandemic in the past 120 years. In all three of these respects, there is no close historic parallel to the COVID-19 contraction. This conclusion underscores the need for forward-looking measures of uncertainty and other economic indicators. The unprecedented nature of the COVID-19 economic crisis also provides some insight into why uncertainty has skyrocketed in its wake.

\section{Forward-Looking Uncertainty Measures}

We now consider several types of forward-looking uncertainty measures.

Stock Market Volatility: Examples include the 1-month and 24-month VIX, which quantify the option-implied volatility of returns on the S\&P 500 index over their respective horizons. The 1-month VIX rose from about 15 in January 2020 to a peak daily value of 82.7 on 16 March before falling below 30 by early May. The second-highest daily value in the history of the 1month VIX, which dates back to 1990, was 80.9 on 27 October 2008.

Figure 1 plots the evolution of weekly-average values for the 1-month and 24-month VIX. The two series behave similarly in 2020, although the amplitude of the peak upward fluctuation is considerably smaller for the 24-month VIX. To push further back in time, one can calculate

\footnotetext{
${ }^{8}$ The US excess mortality from 1918 to 1920 was 0.52 percent of population (Table 1 in Barro et al., 2020).

${ }^{9}$ The main text focuses on the US experience, but the size of the COVID-19 mortality shock to date varies greatly among advanced economies. In the United Kingdom, one of the worst-hit countries, COVID-19 has caused an estimated 59,500 excess deaths to date and an excess mortality rate of about 0.09 percent of the population. By way of comparison, Germany has an excess mortality rate of only 0.009 percent. See footnote 6 for data sources.
} 
the realized volatility of daily market returns using short look-back windows that quickly capture abrupt changes in economic circumstances. Baker, Bloom, Davis, Kost, Sammon and Viratyosin (2020) take this approach. They find five great realized return volatility episodes. Ordered by peak volatility, they are October 1987, the stock market crash of 1929, the coronavirus pandemic in March 2020, March 1933 near the trough of the Great Depression, and December 2008 during the Global Financial Crisis.

Newspaper-Based Uncertainty Measures: Examples include the Economic Policy Uncertainty Indices of Baker, Bloom and Davis (2016). ${ }^{10}$ The daily version of this index reflects the frequency of newspaper articles with one or more terms about "economics," "policy" and "uncertainty" in roughly 2,000 US newspapers. It is normalized to 100 from 1985 to 2010, so values above 100 reflect higher-than-average uncertainty. Figure 2 plots weekly averages of the daily EPU, which surges from around 100 in January 2020 to over 500 in March and April 2020, reaching its the highest values on record. The monthly US EPU index based on a balanced panel of major US newspapers displays a similar pattern and also reaches its highest values on record in March, April and May 2020. ${ }^{11}$

Newspaper-based measures of uncertainty are forward looking in that they reflect the realtime uncertainty perceived and expressed by journalists. They stretch back to 1900 for the United States and are now available for dozens of countries at www.policyuncertainty.com. They also offer a ready ability to drill down into the sources of economic uncertainty and its movements over time, as contemporaneously perceived. For example, over $90 \%$ of newspaper articles about economic policy uncertainty in March 2020 mention "COVID," "Coronavirus," "pandemic" or other term related to infectious diseases.

Baker, Bloom, Davis and Kost (2019) develop a newspaper-based Equity Market Volatility (EMV) tracker that closely mirrors movements in the VIX. Their index lends itself to a quantitative exploration of news developments that drive stock market volatility, again as contemporaneously perceived by journalists. Applying their approach to infectious diseases, they find that COVID-19 is the dominant topic in newspaper articles about stock market volatility

\footnotetext{
${ }^{10}$ Available at www.policyuncertainty.com. See, also, the World Uncertainty Index of Ahir, Bloom and Furceri (2019) at www.worlduncertaintyindex.com, which uses Economist Intelligence Unit reports instead of newspapers.

11 The monthly EPU index is available at http://www.policyuncertainty.com/us monthly.html.
} 
since the last week in February. In comparison, Ebola, SARS, H1N1 and other infectious disease outbreaks since 1985 made only minor contributions to stock market volatility.

Twitter-Based Economic Uncertainty: To construct a twitter-based economic uncertainty index (TEU), we scraped all tweets worldwide that contain both "economic" and "uncertainty" (including variants of each term) from 1 January 2010 to 1 June $2020 .{ }^{12}$ This yields about 175,000 tweets. We then computed the weekly EU tweet frequency. Figure 2 plots the weekly TEU series alongside the weekly newspaper-based EPU index. The two series behave similarly around the COVID-19 crisis.

Subjective Uncertainty Measures Computed from Business Expectation Surveys: Examples include the US monthly panel Survey of Business Uncertainty (SBU) and the UK monthly Decision Maker Panel (DMP).$^{13}$ These panel surveys recruit participants by phone from databases that cover nearly all public and private companies with employees (about 7 million in the US and about 1 million in the UK). The SBU has around 400 respondents per month, and the DMP has around 3,000. Core survey questions elicit five-point probability distributions (mass points and associated probabilities) over each firm's own future sales growth rates at a one-year look-ahead horizon. By calculating each firm's subjective standard deviation about its own future growth rate forecast in a given month, and aggregating over firms in that month, we obtain an aggregate measure of subjective uncertainty about future sales growth rates.

Figure 3 plots these survey-based time-series measures of sales growth rate uncertainty for the United States and the United Kingdom. These measures show pronounced increases in uncertainty in March 2020 and April 2020, before falling back slightly in May 2020. But all three months are well above any previous peaks in their (short) histories. See Altig et al (2020c) for evidence that firm-level growth expectations in the SBU are highly predictive of realized growth rates, and that firm-level subjective uncertainty predicts the magnitudes of future forecast errors and future forecast revisions.

Figure 4 (left panel) draws on data from the UK Decision Maker Panel to depict how COVID-induced uncertainty rose rapidly in March 2020. Specifically, we exploit the large DMP sample to split the survey response periods and subdivide the monthly data. We see uncertainty -

\footnotetext{
${ }^{12}$ See Baker, Bloom, Davis and Renault (2020) for details.

${ }^{13} \mathrm{At}$ www.frbatlanta.org/research/surveys/business-uncertainty and http://decisionmakerpanel.com/
} 
measured here as the percentage of firms reporting that COVID is "their single largest source of uncertainty" - rose from about $25 \%$ at the beginning of March to almost $90 \%$ by early April, and slowly fell back to about $60 \%$ by late May. So, COVID became the overwhelmingly dominant source of uncertainty for UK firms within a period of less than four weeks. This pattern for the UK confirms the US-oriented evidence in Section 2 that the COVID-19 crisis unfolded with extraordinary speed.

The right panel in Figure 4 exploits another DMP question to illustrate how COVID-related concerns rapidly displaced Brexit-related concerns as the top source of uncertainty for firms in the United Kingdom. Before the COVID-19 crisis unfolded, roughly 15-25 percent of DMP respondents fingered Brexit-related concerns as their top source of uncertainty. By March 2020, that share fell to nearly zero, as COVID-related concerns became the dominant source of uncertainty for almost all firms. The fact that COVID so rapidly displaced Brexit - itself a huge source of uncertainty - highlights the extreme character of COVID-induced uncertainty.

These business expectation surveys are valuable for measuring what firms actually perceive in real time. They yield actionable data within 5 to 20 days of when the survey first goes to field. Their main downside is the cost of building the sample and fielding the survey each month, and the need to accumulate data for comparisons over time. Once in place, however, these surveys are highly flexible and allow for rapid deployment of special questions that target current developments and policy issues. They also allow analysis of uncertainty by region, industry, firm size and age, and growth rates. As an illustration, appendix figures A1 and A2 report UK and US subjective uncertainty data broken down by firm size and broad sector.

Forecaster Disagreement: Figure 5 compares US and UK disagreement among professional forecasters about one-year-ahead GDP growth rate forecasts. The US data are from the Survey of Professional Forecasters (SPF), ${ }^{14}$ while the UK data are from the Survey of External Forecasters (SEF). There is a long history of using such disagreement measures to proxy for uncertainty, and also a long history of disagreement about their suitability for that purpose. Our view is that at least for real variables like GDP growth, high levels of disagreement are reasonable proxies for high levels of economic uncertainty. To quantify disagreement, we calculate the standard-

\footnotetext{
${ }^{14}$ See https://www.philadelphiafed.org/research-and-data/real-time-center/survey-of-professional-forecasters.
} 
deviation of GDP growth rate forecasts across forecasters. There are, on average, 41 forecasters per survey response period in the US and 23 in the UK.

As seen in Figure 5, the COVID-19 pandemic triggered historically high levels of disagreement in the growth rate forecasts. US disagreement rose from a standard deviation 0.32 percentage points in 2020Q1 to 2.74 in 2020Q2, a rise of nearly 8-fold. UK forecast disagreement rose from 0.49 percentage points to 10.1 , an astounding 20 -fold increase.

\section{Comparing the Uncertainty Measures}

Armed with these uncertainty measures, we turn now to three questions: How much did uncertainty rise in the wake of the COVID pandemic? When did it peak? How much, if it all, has it fallen since the peak?

Table 1 summarizes our answers: First, every uncertainty measure we consider rose sharply in the wake of the COVID-19 pandemic. Most measures reached all-time peaks. The exceptions are the 24-month VIX, which peaked during the Global Financial Crisis, and the US GDP forecast disagreement measure, which peaked in the 1970s.

Second, there is huge variation in the magnitude of the increase. Subjective uncertainty over sales growth rates at a one-year forecast horizon roughly doubles, as does the 24-month VIX. In contrast, disagreement among professional forecasters about real GDP growth over the next year rises roughly 8 -fold for the United States and 20-fold for the United Kingdom. The much greater rise in macro uncertainty, as compared to the rise in average firm-level uncertainty, reflects the nature of the COVID-19 shock. It is a huge common shock that hit all firms. Normally, even in recessions, common shocks are modest in size, and firm-level uncertainty is mainly driven by idiosyncratic shocks that are largely diversified away at the aggregate level. Thus, the prepandemic level of background risk is much greater at the firm level than at the aggregate level. ${ }^{15}$ A big jump in a common source of uncertainty triggers a larger percentage increase in macro uncertainty measures than micro ones. The smaller rise in subjective uncertainty over sales growth might also reflect the way the data are measured. They refer to expectations for sales in a single quarter a year ahead. For example the May 2020 Decision Maker Panel data refer to sales

\footnotetext{
${ }^{15}$ The smaller percentage rise in subjective uncertainty about firm-level growth rates in the United Kingdom, as compared to the United States, also makes sense. U.K. firms were already contending with Brexit-related uncertainty before the pandemic struck.
} 
expectations for $2021 \mathrm{Q} 1$ and so does not cover the peak period of economic disruption in 2020 Q2 and Q3.

The 1-month VIX, the newspaper-based EPU index, and the Twitter EU index also show large upward spikes (in percentage terms) in the wake of the COVID-19 shock. The 1-month VIX focuses on the near term by construction, and the text-based measures are also likely to give more attention to near-term sources of uncertainty rather than distant-future uncertainty. In addition, the text-based measures reflect a mix of macro and micro uncertainty, probably with a larger weight on the former.

Third, the time profiles of uncertainty responses to the COVID-19 shock differ across the various measures. The stock market volatility measures peaked relatively early, as reported in Table 1. The broader, real-side measures peaked later.

Figure 6 offers a close-up look at the recent behavior of several uncertainty measures that we can track at sub-monthly intervals. We include a Likert-based measure for the UK derived from responses to the following DMP question: "How would you rate the overall level of uncertainty facing your business at the moment?" Response options are "Very high - very hard to forecast future sales," "High - hard to forecast future sales," "Medium - future sales can be approximately forecasted," "Low - future sales can be accurately forecasted," and "Very low future sales can be very accurately forecasted." We display the percentage of firms that report high or very high uncertainty in response to this question.

Figure 6 shows that the stock market volatility measures peak in mid-March and then fall quickly to about half their peak levels by the end of May. In contrast, the real-side uncertainty measures peak later - or continue to remain extremely high through late May in the case of subjective uncertainty. This contrast highlights the Wall Street/Main Street distinction that is also apparent in first-moment outcomes. The S\&P 500 index bottomed out on 23 March 2020, having dropped 34 percent from its level on 19 February. Since then, the market has risen sharply, recovering three-quarters of its losses by the end of May as measured by the S\&P 500 index. This stock market recovery began only a few days after the start of the job loss tsunami that we recounted in Section 2.

\section{Conclusions}


We have examined a variety of forward-looking indicators of economic uncertainty. Three results emerge. First, all indicators show huge uncertainty jumps in reaction to the pandemic and its economic fallout. Indeed, most indicators reach their highest values on record. Second, peak amplitudes differ greatly - from an 80 percent rise (relative to January 2020) in two-year implied volatility on the S\&P 500 to a 20 -fold rise in forecaster disagreement about UK growth. Third, time paths also differ: Implied stock market volatility rose rapidly from late February, peaked in mid-March, and fell back by late March as stock prices partly recovered. In contrast, broader measures peaked later, as job losses continued to mount, and they plateaued or continued rising after March.

We also marshalled evidence that the COVID-19 pandemic and its economic fallout lack close historic parallels in at least two respects: First, the suddenness and enormity of the massive job losses and, second, the severity of the economic contraction relative to the size of the mortality shock. The unprecedented scale and nature of the COVID-19 crisis helps explain why it has generated such an extraordinary surge in economic uncertainty.

It remains to be seen which uncertainty measures will prove most useful in explaining economic developments during and after the COVID-19 pandemic. Our prior is that several, and perhaps all, of these measures will prove useful, because they capture different aspects of economic uncertainty. For example, the subjective uncertainty measures are particularly apt for theories that stress the role of firm-level risks in economic fluctuations (e.g., Christiano et al., 2014). The VIX measures are obviously more apt for theories that link asset-pricing behavior to economic fluctuations. The EPU measures are highly relevant for theories that link asset-pricing to political decision-making in reaction to macroeconomic developments (e.g., Pastor and Veronesi, 2012). The newspaper-based and Twitter-based measures are perhaps more closely aligned with the perceptions of households. All of the uncertainty measures we consider are potentially useful in testing and implementing theories about investment and consumption under uncertainty. Indeed, many of them have been used to that end in previous studies. ${ }^{16}$

Finally, we should point out that these continuing high-levels of uncertainty do not bode well for a rapid economic recovery. Elevated uncertainty generally makes firms and consumers cautious, retarding investment, hiring and expenditures on consumer durables. See, for example,

\footnotetext{
${ }^{16}$ See Bloom (2014) and Baker et al. (2016) for references.
} 
Bernanke (1983), Dixit and Pindyck (1994), Abel and Eberly (1996) and Bertola, Guiso and Pistafferi (2005). Given the scale of recent job losses and the collapse in investment, a strong, rapid recovery would require a huge surge in new activity, which unprecedented levels of uncertainty will discourage. 


\section{References}

Abel, Andrew and Janice Eberly, 1996. "Optimal investment with costly reversibility," Review of Economic Studies, 63, no. 4, 581-593.

Ahir, Hites, Nicholas Bloom and Davide Furceri, 2019. "The World Uncertainty Index," Stanford mimeo.

Alfaro, Laura, Anusha Chari, Andrew Greenland and Peter K. Shott, 2020. "Aggregate and Firm-Level Stock Returns during Pandemics, in Real Time," working paper, 2 April.

Altig, David, Jose Maria Barrero, Nick Bloom, Steven J. Davis, Brent Meyer, Emil Mihaylov and Nick Parker, 2020a. "American Firms Foresee a Huge Negative Impact of the Coronavirus," Technical Report, Federal Reserve Bank of Atlanta, 23 March.

Altig, David, Jose Maria Barrero, Nick Bloom, Steven J. Davis, Brent Meyer, Emil Mihaylov and Nick Parker, 2020b. "Firms Expect Working from Home to Triple," Technical Report, Federal Reserve Bank of Atlanta, 28 May.

Altig, David, Jose Maria Barrero, Nick Bloom, Steven J. Davis, Brent Meyer and Nick Parker, 2020c. "Surveying Business Uncertainty" NBER Working Paper 25956. Revised, March 2020. Forthcoming, Journal of Econometrics.

Anderson, Roy M., Hans Heersterbeek, Don Klinkenberg, and T. Dierdre Hollingsworth, 2020. "How will country-based mitigation measures influence the course of the covid-19 epidemic?" The Lancet, 395, no. 10228 (March).

Atkeson, Andrew, 2020a. "How Deadly Is Covid-19? Understanding the Difficulties with Estimation of Fatality Rate," working paper, 31 March 2020.

Atkeson, Andrew, 2020b. "What Will Be the Economic Impact of COVID-19 in the US? Rough Estimates of Disease Scenarios," NBER Working Paper 26867, March.

Baker, Scott, Nicholas Bloom and Steven J. Davis, 2016. "Measuring Economic Policy Uncertainty," Quarterly Journal of Economics, November.

Baker, Scott Baker, Nicholas Bloom, Steven J. Davis and Kyle Kost, 2019. "Policy News and Equity Market Volatility," NBER working paper 25720.

Baker, Scott R., Nicholas Bloom, Steven J. Davis, Kyle Kost, Marco Sammon, and Tasaneeya Viratyosin, 2020. "The Unprecedented Stock Market Reaction to COVID-19," Covid Economics: Vetted and Real-Time Papers, Issue 1, 3 April 2020.

Baker, Scott Baker, Nicholas Bloom, Steven J. Davis and Thomas Renault, 2020. "Economic Uncertainty Measures Derived from Twitter," working paper, June.

Baker, Scott, Nicholas Bloom, Steven J. Davis, Kyle Kost, Marco Sammon and Tasaneeya Viratyosin, 2020. "The Unprecedented Stock Market Reaction to COVID-19" Covid Economics: Vetted and Real-Time Papers, 1, 3 April.

Baker, Scott, Nicholas Bloom, Steven J. Davis and Stephen Terry, 2020. "COVID-Induced Economic Uncertainty," NBER Working Paper No. 26983.

Barrero, Jose, Nicholas Bloom and Steven J. Davis, 2020. "COVID-19 Is Also a Reallocation Shock," NBER Working Paper No. 27137.

Barrero, Jose, Nicholas Bloom and Ian Wright, 2017. "Short and long run uncertainty," NBER Working Paper 23676.

Barro, Robert J., Jose F. Ursua and Joanna Weng, 2020. "The Coronavirus and the Great Influenza Pandemic: Lessons from the 'Spanish Flu' for the Coronavirus's Potential Effects on Mortality and Economic Activity,” NBER Working Paper 26866, revised April 2020. 
Bendavid, Eran and Jay Bhattacharya, 2020. "Is Coronavirus as Deadly as They Say?" Wall Street Journal, 24 March.

Bernanke, Ben, 1983. "Irreversibility, uncertainty, and cyclical investment," Quarterly Journal of Economics, 98, no. 1, 85-106.

Bertola, Giuseppe, Luigi Guiso, and Luigi Pistaferri, 2005. "Uncertainty and consumer durables adjustment," Review of Economic Studies, 72, no. 4, 973-1007.

Bloom, Nicholas "Fluctuations in Uncertainty, 2014. Journal of Economic Perspectives, Spring 2014.

Bloom, Nicholas, Scarlet Chen, Phil Bunn, Paul Mizen, Pawel Smietanka and Greg Thwaites (2019), "The impact of Brexit on UK firms," NBER Working Paper 26218, September.

Christiano, Lawrence J., Roberto Motto and Massimo Rostagno, 2014. "Risk Shocks," American Economic Review, 104, no. 1, 27-65.

Correia, Sergio, Stephen Luck and Emil Verner, 2020. "Pandemics Depress the Economy, Public Health Interventions Do Not: Evidence from the 1918 Flu," working paper, 10 April.

Croushore, Dean and Tom Stark, 2019. "Fifty Years of the Survey of Professional Forecasters," Economic Insights, Federal Reserve Bank of Philadelphia.

Dewatripont, Mathias, Michel Goldman, Eric Muraille and Jean-Philippe Platteau, 2020. "Rapidly Identifying Workers Who Are Immune to COVID-19 and Virus-Free Is a Priority for Restarting the Economy," VOX CEPR Policy Portal, 23 March.

Dew-Becker, Ian and Stefano Giglio, 2020. "Cross-sectional uncertainty and the business cycle: Evidence from 40 years of options data," working paper.

Dixit, Avinash and Robert Pindyck (1994). Investment under uncertainty. Princeton: Princeton University Press.

Eichenbaum, Martin S., Sergio Rebelo and Mathias Trabandt, 2020. "The Macroeconomics of Epidemics," NBER Working Paper 26882, March.

Fauci, Anthony S., H. Clifford Lane and Robert R. Redfield, 2020. "Covid-19 - Navigating the Uncharted," New England Journal of Medicine, 26 March. DOI: 10.1056/NEJMe2002387.

Ferguson, Neil et al., 2020. "Impact of Non-Pharmaceutical Interventions to Reduce Covid-19 Mortality and Healthcare Demand," Imperial College COVID-19 Response Team.

Ferguson, Niall, 2020. "1918, 1957, 2020: Big Pandemics and their Economic, Social and Political Consequences," working paper, 20 May.

Glezen, W. Paul, 1996. "Emerging Infections: Pandemic Influenza," Epidemiologic Review, 18, no. 1, 64-76.

Guerreri, Veronica, Guido Lorenzoni, Ludwig Straub and Ivan Werning, 2020. "Macroeconomic Implications of COVID-19: Can Negative Supply Shocks Cause Demand Shortages?” working paper, 2 April.

Jorda, Ocar, Sanjay R. Singh and Alan M. Taylor, 2020. "Longer-Run Economic Consequences of Pandemics," Covid Economics: Vetted and Real-Time Papers, 1, 3 April.

Jurado, Kyle, Sydney Ludvigson and Serena Ng, 2015. "Measuring Uncertainty," American Economic Review, 105, no. 3 (March).

Leduc, Sylvain and Zheng Liu, 2020. "The Uncertainty Channel of the Coronavirus," Economic Letters, Federal Reserve Bank of San Francisco, 30 March.

Li, Ruiyun, Sen Pei, Bin Chen, Yimeng Song, Tao Zhang, Wan Yang and Jeffrey Shaman, 2020. "Substantial Undocumented Infection Facilitates the Rapid Dissemination of Novel Coronavirus (SARS-CoV2)," Science, 16 March. DOI: 10.1126/science.abb3221. 
Linton, N.M. et al., 2020. "Incubation period and other epidemiological characteristics of 2019 novel Coronavirus infections with right truncation: A statistical analysis of publicly available case data," Journal of Clinical Medicine 9, no. 2 (17 February).

Pastor, Lubos and Pietro Veronesi, 2012. "Uncertainty about Government Policy and Stock Prices," Journal of Finance, 67, no. 4, 1219-1264.

Romer, Paul and Rajiv Shah, 2020. "Testing Is Our Way Out," Wall Street Journal, 3 April.

Stock, James H., 2020a. "Data Gaps and the Policy Response to the Novel Coronavirus," NBER Working Paper 26902, March,

Stock, James H., 2020b. "Random Testing Is Urgently Needed," 23 March.

Toda, Alexis Akira, 2020. "Susceptible-Infected-Recovered (SIR) Dynamics of Covid-19 and Economic Impact," Covid Economics: Vetted and Real-Time Papers, 1, 3 April.

Velde, Francois, 2020. "What Happened to the US Economy During the 1918 Influenza Pandemic? A View Through High-Frequency Data," Federal Reserve Bank of Chicago Working Paper 2020-11, 17 April.

Viboud, Cecile, Lone Simonsen, Rodrigo Fuentes, Jose Flores, Mark A. Miller and Gerardo Chowell, 2016. "Global Mortality Impact of the 1957-1959 Influenza Pandemic," Journal of Infectious Diseases, 213, no. 5, 1 March, 738-745.

Vogel, Gretchen, 2020. "New blood tests for antibodies could show true scale of coronavirus pandemic," Science, 19 March. 
Table 1: Measures of Uncertainty for the United States for the COVID-19 Crisis

\begin{tabular}{|c|c|c|c|c|}
\hline Measure & $\begin{array}{l}\text { Average } \\
\text { Value in } \\
\text { January } \\
2020\end{array}$ & $\begin{array}{l}\text { Percentage } \\
\text { Jump Jan } \\
2020 \text { to } \\
\text { Peak }\end{array}$ & $\begin{array}{l}\text { Date of } \\
\text { Peak Value } \\
\text { During } \\
\text { COVID } \\
\end{array}$ & Source \\
\hline VIX 1-Month implied volatility, US & 13.3 & 497 & March 16 & www.cboe.com/vix \\
\hline VIX 24-Month implied volatility, US & 16.2 & 108 & March 18 & Dew-Becker and Giglio \\
\hline Economic Policy Uncertainty, US & 110.1 & 683 & May 26 & www.economicuncertainty.com \\
\hline Twitter Economic Uncertainty, US & 139.8 & דילני & April 22-28 & Baker, Bloom, Davis and Ren \\
\hline Subjective Sales Growth Uncertainty, US & 2.7 & 154 & April 2020 & www.frbatlanta.org/research/surveys/business-uncertainty \\
\hline Subjective Sales Growth Uncertainty, UK & 4.3 & 91 & April 2020 & akerpanel.com \\
\hline Forecaster disagreement, US & 0.3 & 755 & $2020 \mathrm{q} 2$ & $\begin{array}{l}\text { www.philadelphiafed.org/research-and-data/real-time- } \\
\text { center/survey-of-professional-forecasters/data-files/rgdp }\end{array}$ \\
\hline Forecaster disagreement, UK & 0.5 & 1960 & $2020 q 2$ & $\begin{array}{l}\text { www.bankofengland.co.uk/report/2020/monetary-policy- } \\
\text { report-financial-stability-report-may-2020 }\end{array}$ \\
\hline \multicolumn{5}{|c|}{$\begin{array}{l}\text { Notes: The VIX is the implied volatility (over the next month and over the next } 24 \text { months) on the S\&P500 index from the Chicago Board } \\
\text { of Options Exchange, expressed in annualized units. Values downloaded from: https://fred.stlouisfed.org/series/VIXCLS. The daily } \\
\text { Economic Policy Uncertainty index values are from www.policyuncertainty.com/media/All_Daily Policy_Data.csv and constructed as } \\
\text { described in Baker, Bloom and Davis (2016). Subjective sales growth uncertainty is computed as the activity-weighted average of firm- } \\
\text { level subjective uncertainty values, which are computed as the standard deviation of each firm's subjective forecast distribution over its } \\
\text { own future sales growth rate from the current quarter to four quarters hence. See Altig et al., 2020c). US data are form the Survey of } \\
\text { Business Uncertainty conducted by the Federal Reserve Bank of Atlanta, Stanford University, and the University of Chicago Booth School } \\
\text { of Business (https://www.frbatlanta.org/research/surveys/business-uncertainty). UK data are from the Decision Maker Panel Survey } \\
\text { conducted by the Bank of England, Nottingham University and Stanford University (www.decisionmakerpanel.com). Forecast } \\
\text { disagreement is measured as the standard deviation across forecasters of one-year-ahead annual real GDP growth rate forecasts. US data } \\
\text { are from the Survey of Professional Forecasters conducted by the Philadelphia Fed (https://www.philadelphiafed.org/research-and- } \\
\text { data/real-time-center/survey-of-professional-forecasters). UK data are from the Survey of External Forecasters conducted by the Bank of } \\
\text { England, (https://www.bankofengland.co.uk/monetary-policy-report/2020/january-2020/other-forecasters-expectations). }\end{array}$} \\
\hline
\end{tabular}




\section{Figure 1: VIX, Implied Stock Returns Volatility, Weekly Since 1990}

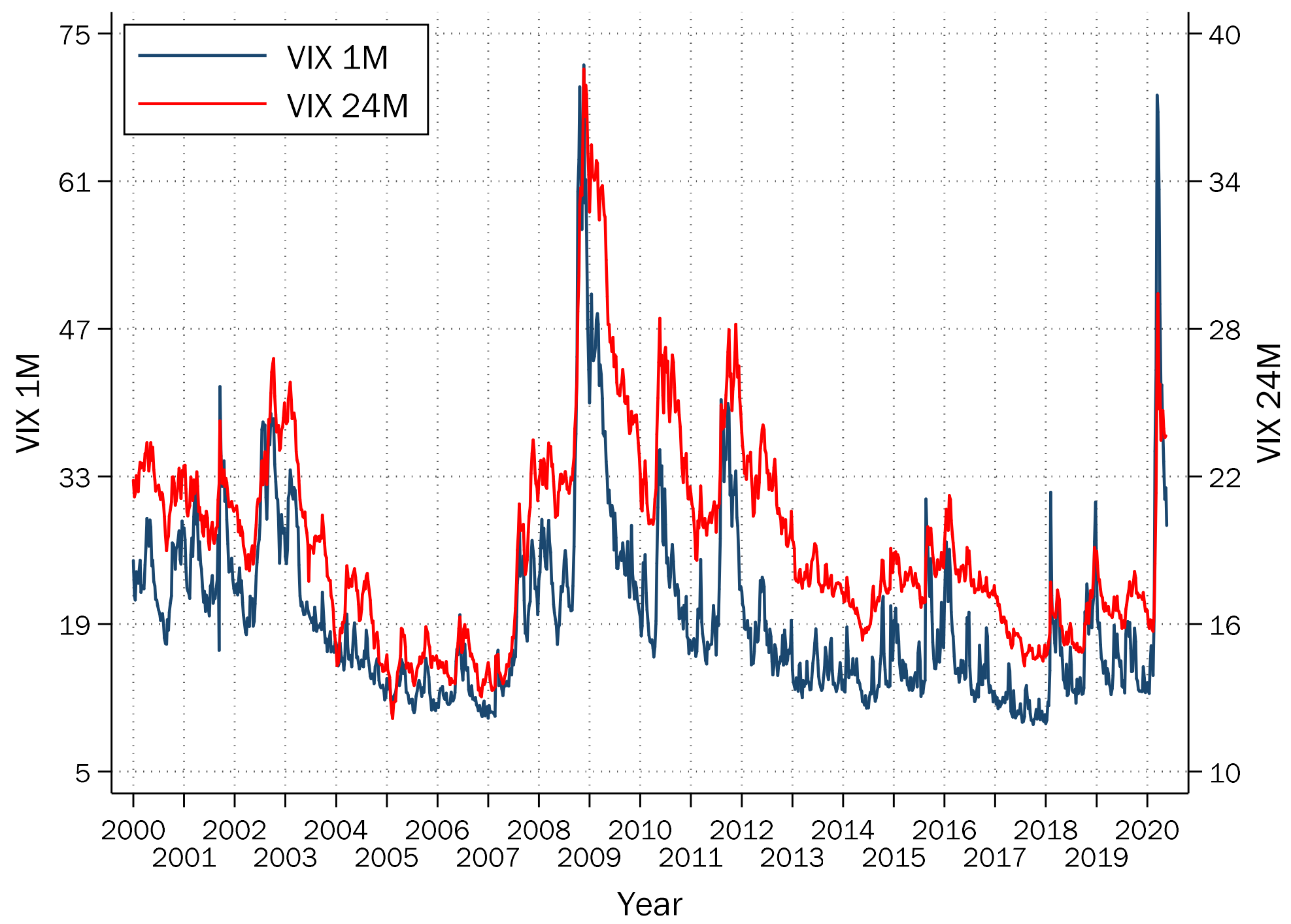

Notes: Weekly implied volatility over the next month on the S\&P500 index from the Chicago Board of Options Exchange, expressed in annualized units. We plot data from 3 January 2000 to 26 May 2020 (18 May 2020 for VIX 24M). Values downloaded from: https://fred.stlouisfed.org/series/VIXCLS. Weekly implied volatility over the next 24 months downloaded from Wharton Research Data Services. Latest data kindly provided by lan L. Dew-Backer. 
Figure 2: U.S. Economic Policy Uncertainty Index and Twitter Economic Uncertainty Index, Weekly Since 1990

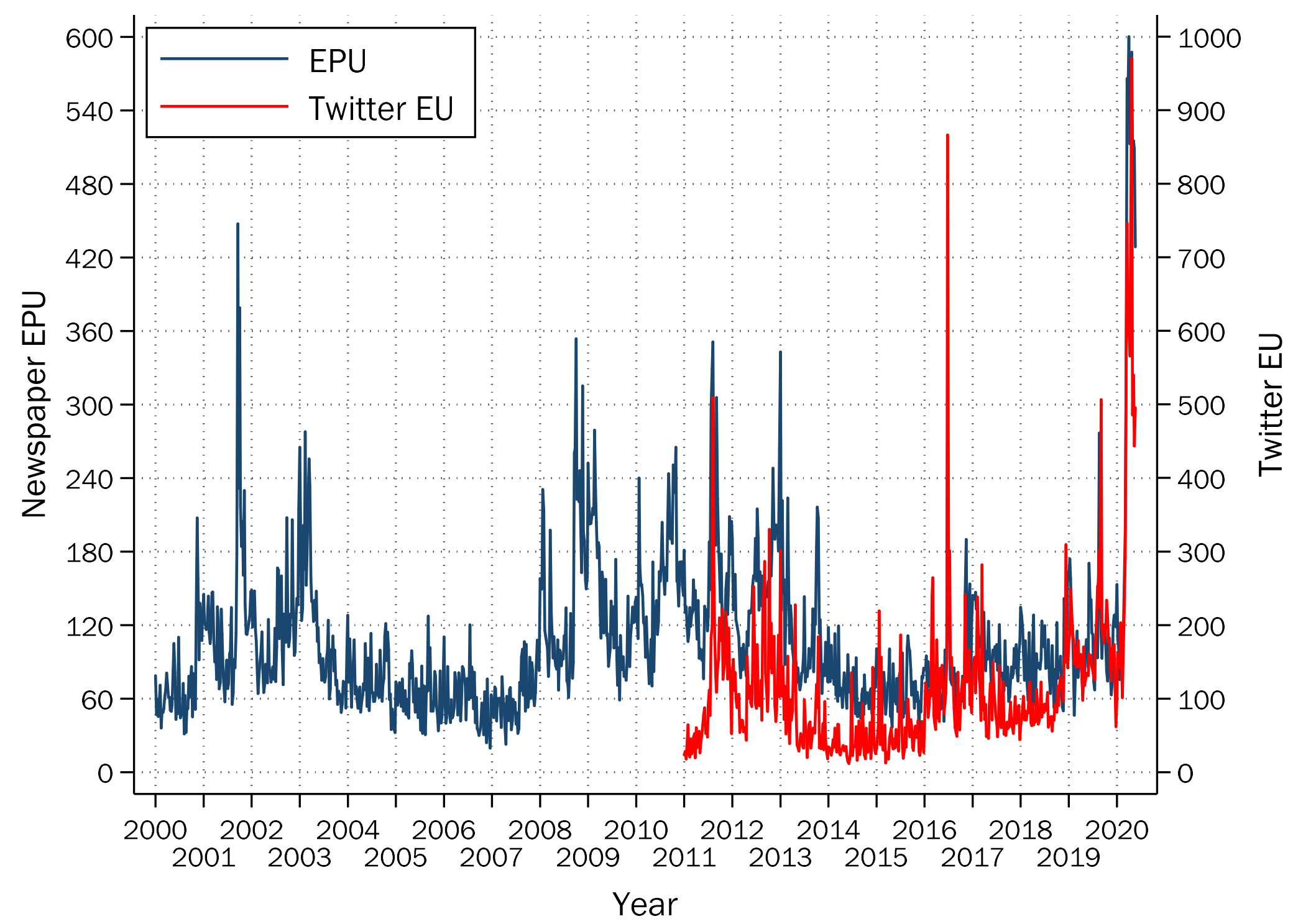

Notes: Weekly values for EPU and Twitter from data from www.policyuncertainty.com/media/All Daily Policy Data.csv. See Baker, Bloom and Davis (2016) for details of index construction. We plot data from 1 January 2000 to 26 May 2020. 


\section{Figure 3: Firm-Level Subjective Sales Uncertainty, Monthly from 2017}

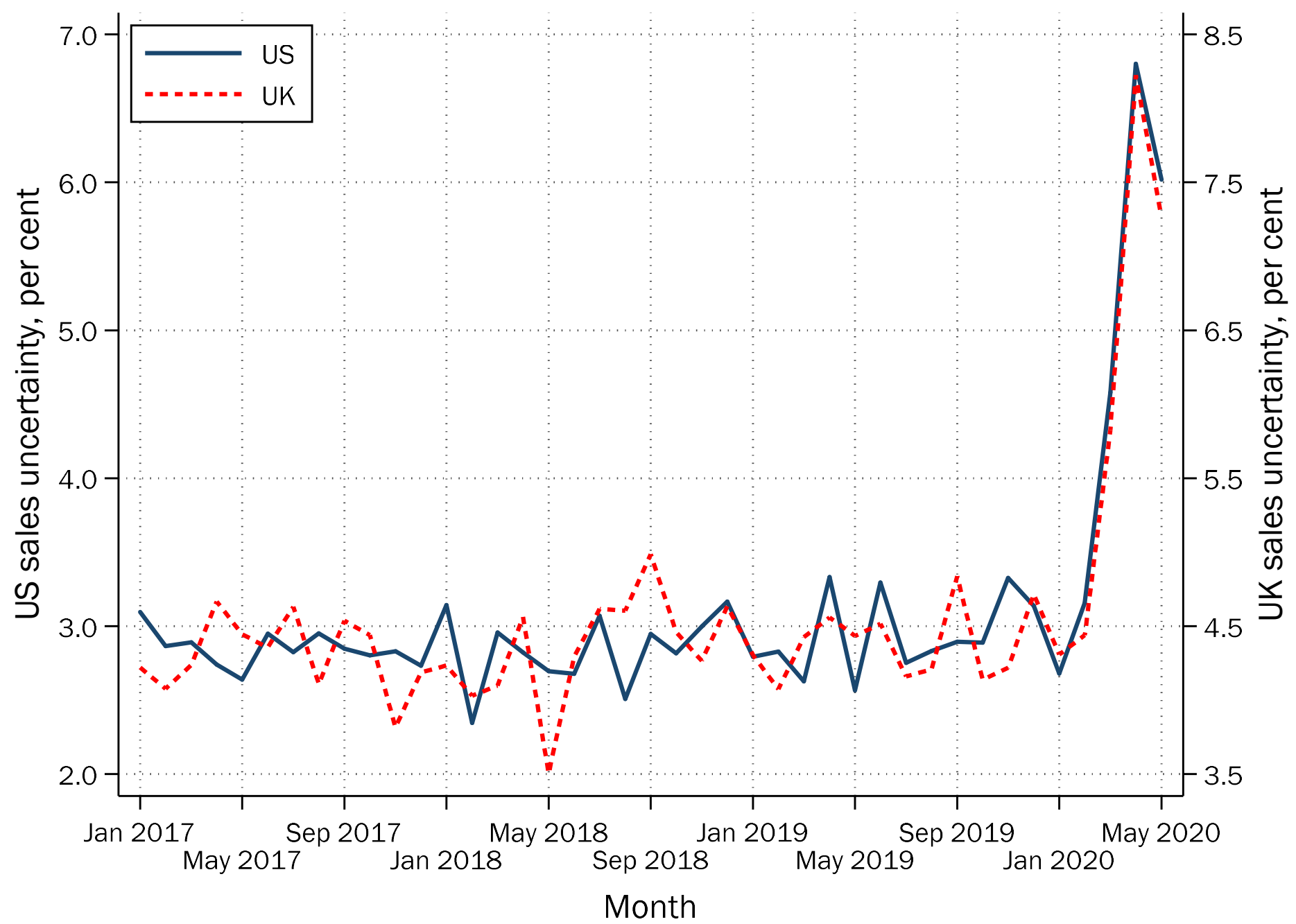

Notes: Subjective uncertainty measured for the growth rate of 4 quarters ahead firm level sales expectations (details in Altig et al. 2020). US data form the Survey of Business Uncertainty conducted by the Federal Reserve Bank of Atlanta, Stanford University, and the University of Chicago Booth School of Business (https://www.frbatlanta.org/research/surveys/business-uncertainty). UK data from the Decision Maker Panel Survey conducted by the Bank of England, Nottingham University and Stanford University (see Bloom et al. (2019) and www. decisionmakerpanel.com). 


\section{Figure 4: COVID-Induced Uncertainty Rose Rapidly in March 2020}

$\%$ firms reporting Covid-19 as their top source of uncertainty
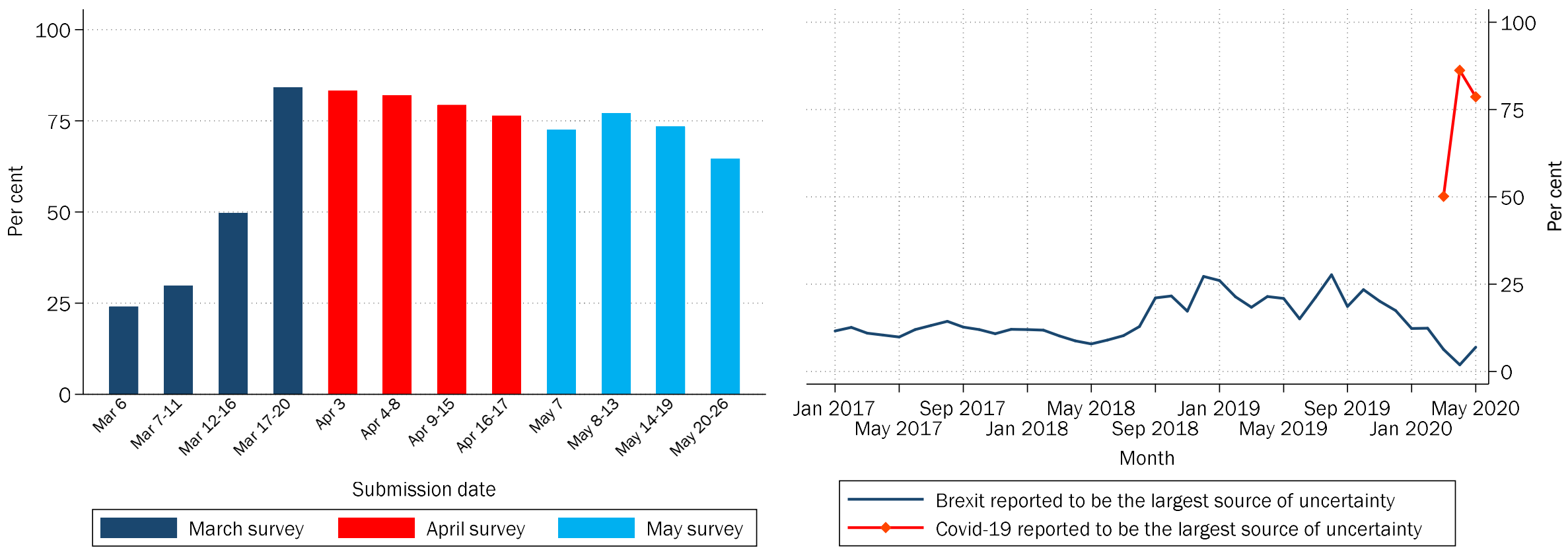

Notes: Decision Maker Panel Survey conducted by the Bank of England, Nottingham University and Stanford University and Bloom et al. (2019) and www.decisionmakerpanel.com 


\section{Figure 5: Cross-sectional dispersion of GDP growth forecasts}

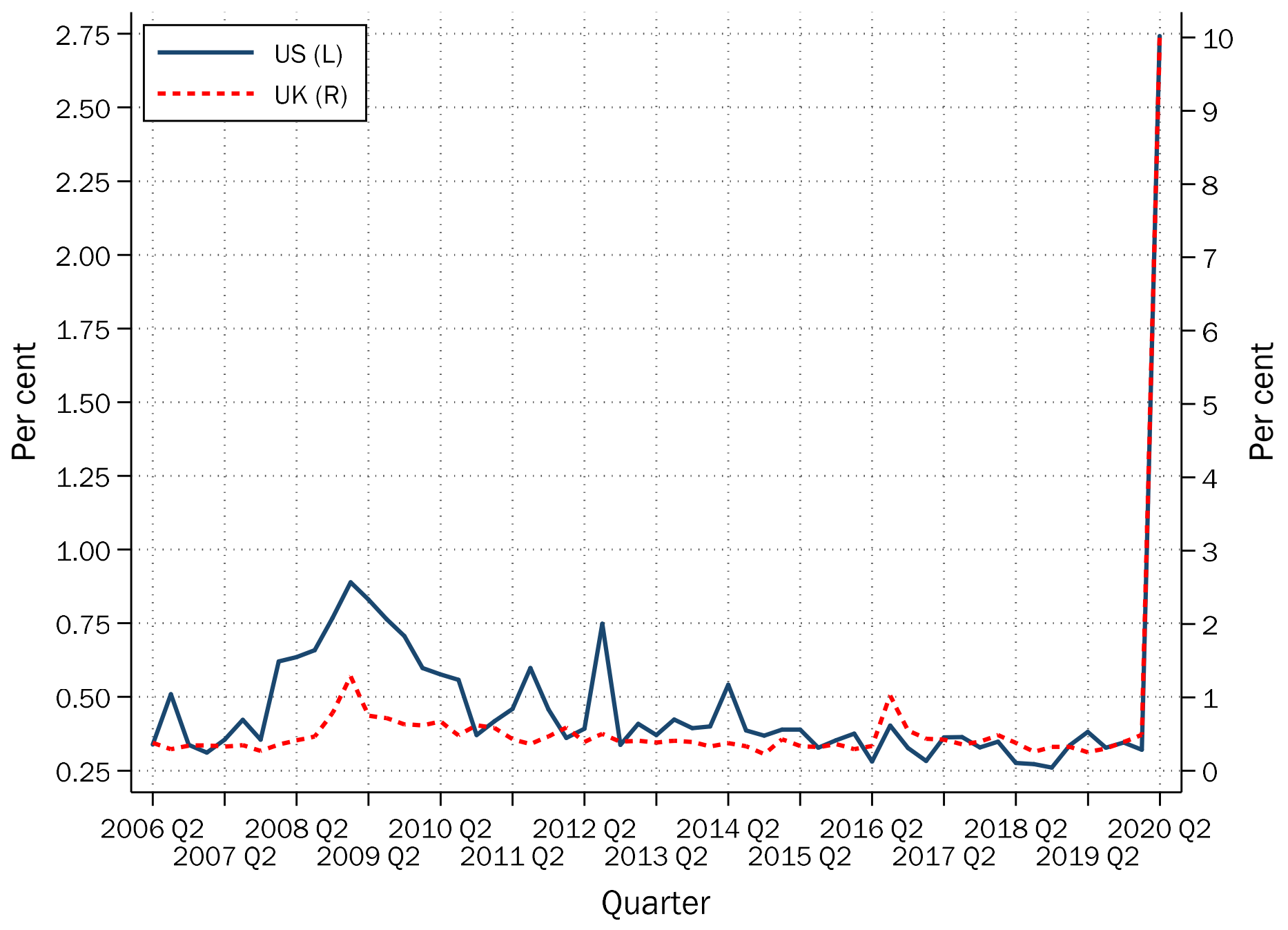

Notes: Chart shows standard deviation of one-year-ahead annual real GDP growth forecasts. US data are from the Survey of Professional Forecasters conducted by the Philadelphia Fed (https://www.philadelphiafed.org/research-and-data/real-time-center/survey-of-professional-forecasters). The deadline for submitting responses to the SPF survey is usually in the first half of February, May, August, and November (see https://www.philadelphiafed.org/-/media/research-and-data/real-time-center/survey-of-professional-forecasters/spf-release-dates.txt). The submission deadline for the latest survey was 12 May 2020. UK data are from the Survey of External Forecasters conducted by the Bank of England, (https://www.bankofengland.co.uk/monetary-policy-report/2020/january-2020/other-forecasters-expectations). The SEF is in the field for two weeks one month ahead of the Bank of England's publication of the Monetary Policy Report. This is usually the second half of January, April, July, and October. The latest SEF survey ended on 24 April 2020. 


\section{Figure 6: COVID uncertainty - high frequency timing}

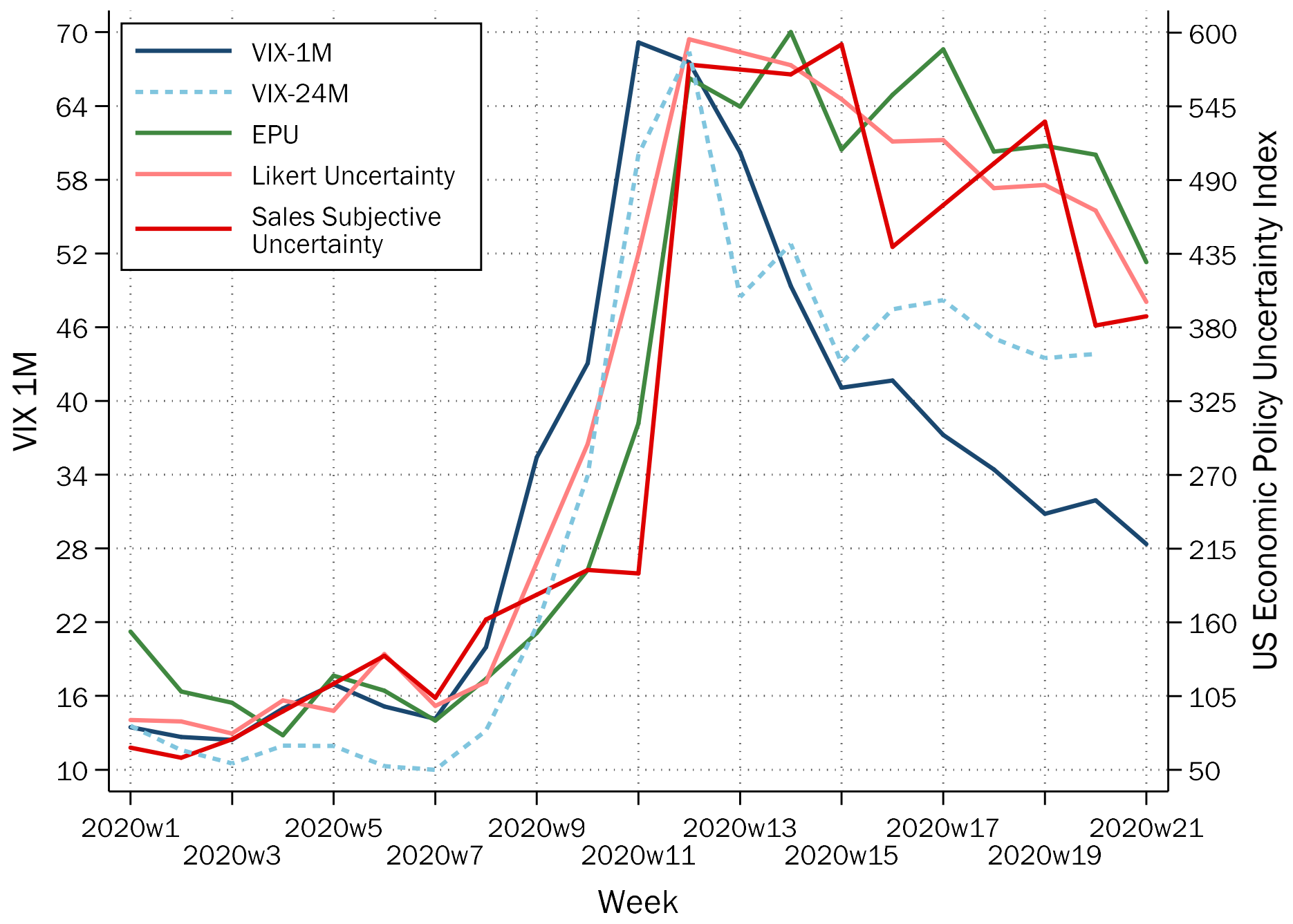

Notes: Decision Maker Panel Survey conducted by the Bank of England, Nottingham University and Stanford University and Bloom et al. (2019) and www.decisionmakerpanel.com. Values linearly interpolated when the DMP survey was not in the field. Values of the Likert Uncertainty measure were extrapolated using information about firms' sales expectations and uncertainty for the first five weeks. VIX-24M, Likert Uncertainty, and Sales Subjective Uncertainty's axes are hidden. 


\section{Figure A1: COVID uncertainty by firm size}
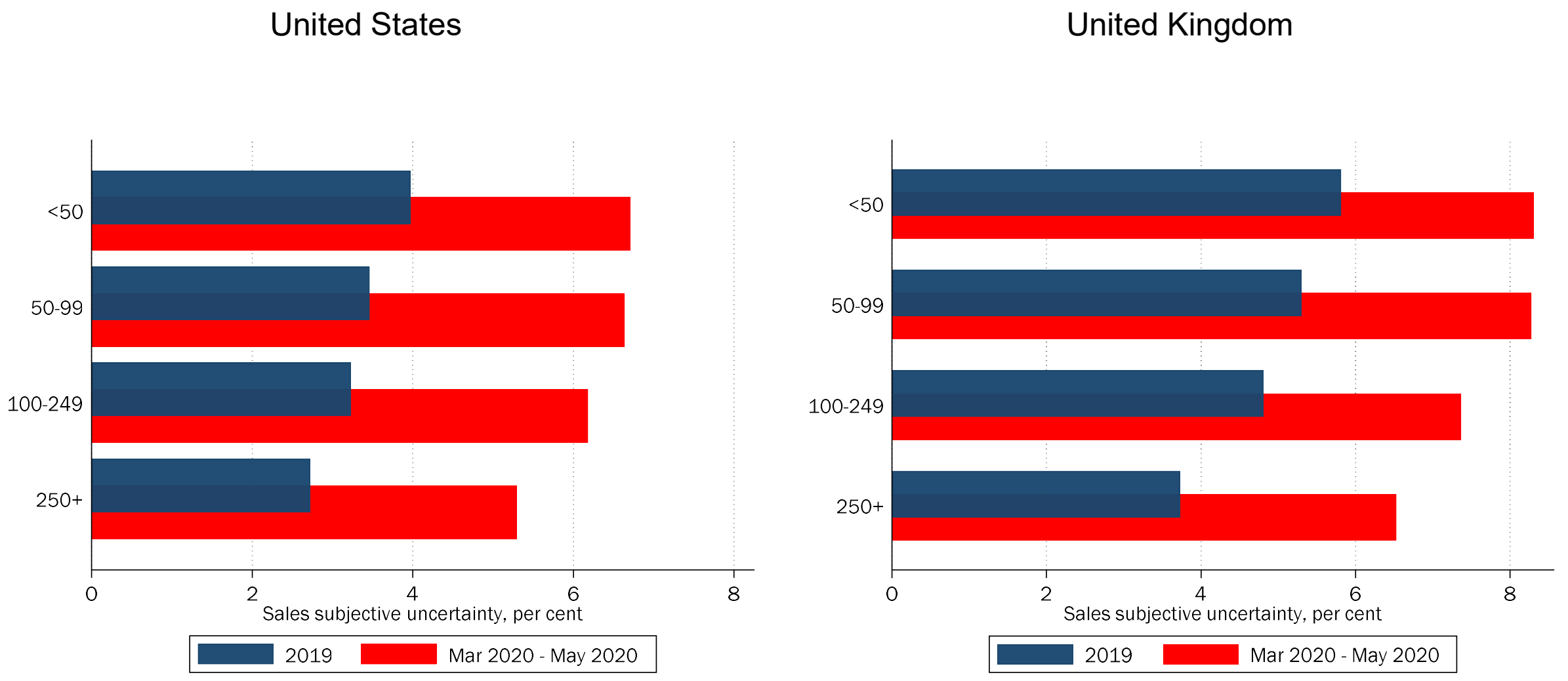

Notes: Subjective uncertainty measured for the growth rate of 4 quarters ahead firm level sales expectations (details in Altig et al. 2020). US data form the Survey of Business Uncertainty conducted by the Federal Reserve Bank of Atlanta, Stanford University, and the University of Chicago Booth School of Business (https://www.frbatlanta.org/research/surveys/businessuncertainty). UK data from the Decision Maker Panel Survey conducted by the Bank of England, Nottingham University and Stanford University (see Bloom et al. (2019) and www.decisionmakerpanel.com). 


\section{Figure A2: COVID uncertainty by industry}
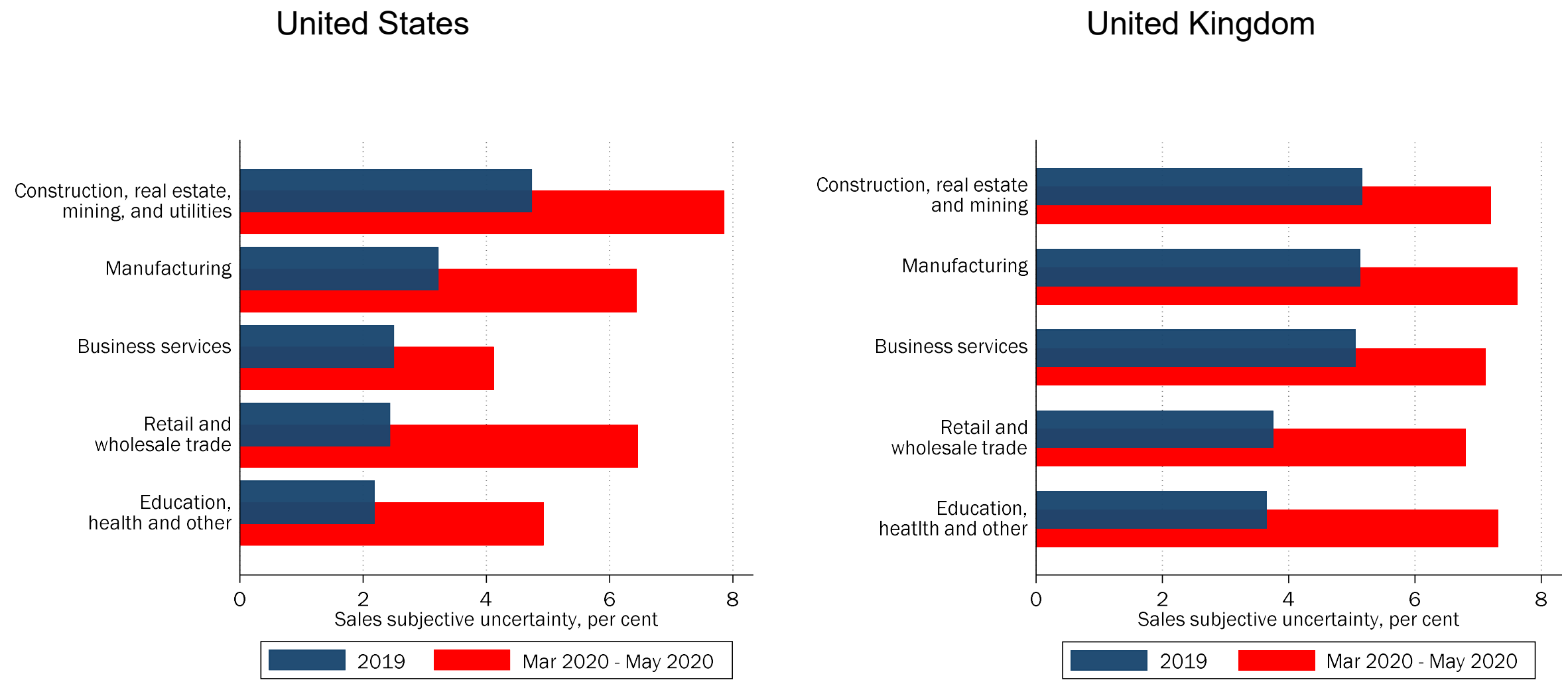

Notes: Subjective uncertainty measured for the growth rate of 4 quarters ahead firm level sales expectations (details in Altig et al. 2020). US data form the Survey of Business Uncertainty conducted by the Federal Reserve Bank of Atlanta, Stanford University, and the University of Chicago Booth School of Business (https://www.frbatlanta.org/research/surveys/businessuncertainty). UK data from the Decision Maker Panel Survey conducted by the Bank of England, Nottingham University and Stanford University (see Bloom et al. (2019) and www.decisionmakerpanel.com). 